\title{
Possible Mechanism of Action of the Antiallergic Effect of an Aqueous Extract of Heliotropium indicum L. in Ovalbumin-Induced Allergic Conjunctivitis
}

\author{
Samuel Kyei, ${ }^{1,2}$ George Asumeng Koffuor, ${ }^{1,3}$ Paul Ramkissoon, ${ }^{1}$ Samuel Abokyi, \\ Osei Owusu-Afriyie, ${ }^{4}$ and Eric Addo Wiredu ${ }^{2}$ \\ ${ }^{1}$ Discipline of Optometry, School of Health Sciences, College of Health, University of KwaZulu-Natal, Durban 4041, South Africa \\ ${ }^{2}$ Department of Optometry, School of Allied Health Sciences, University of Cape Coast, Cape Coast, Ghana \\ ${ }^{3}$ Department of Pharmacology, Faculty of Pharmacy and Pharmaceutical Sciences, \\ Kwame Nkrumah University of Science and Technology, Kumasi, Ghana \\ ${ }^{4}$ Department of Pathology, Komfo Anokye Teaching Hospital, Kumasi, Ghana
}

Correspondence should be addressed to Samuel Kyei; skyei@ucc.edu.gh

Received 17 July 2015; Revised 23 October 2015; Accepted 25 October 2015

Academic Editor: William E. Berger

Copyright (C) 2015 Samuel Kyei et al. This is an open access article distributed under the Creative Commons Attribution License, which permits unrestricted use, distribution, and reproduction in any medium, provided the original work is properly cited.

\begin{abstract}
Heliotropium indicum is used traditionally as a remedy for conjunctivitis in Ghana. This study therefore evaluated the antiallergic potential of an aqueous whole plant extract of Heliotropium indicum (HIE) in ovalbumin-induced allergic conjunctivitis and attempted to predict its mode of action. Clinical scores for allergic conjunctivitis induced by intraperitoneal ovalbumin sensitization $\left(100: 10 \mu \mathrm{g} \mathrm{OVA} / \mathrm{Al}(\mathrm{OH})_{3}\right.$ in phosphate-buffered saline [PBS]) and topical conjunctival challenge (1.5 mg OVA in $10 \mu \mathrm{L}$ PBS) in Dunkin-Hartley guinea pigs were estimated after a week's daily treatment with $30-300 \mathrm{mg} \mathrm{kg}^{-1} \mathrm{HIE}, 30 \mathrm{mg} \mathrm{kg}^{-1} \mathrm{prednisolone}$ $10 \mathrm{mg} \mathrm{kg}^{-1}$ chlorpheniramine, or $10 \mathrm{~mL} \mathrm{~kg}^{-1} \mathrm{PBS}$. Ovalbumin-specific IgG and IgE and total IgE in serum were estimated using Enzyme-Linked Immunosorbent Assay. Histopathological assessment of the exenterated conjunctivae was also performed. The 30 and $300 \mathrm{mg} \mathrm{kg}^{-1}$ HIE treatment resulted in a significantly $(p \leq 0.001)$ low clinical score of allergic conjunctivitis. Ovalbuminspecific IgG and IgE as well as total serum IgE also decreased significantly ( $p \leq 0.01-0.001)$. The conjunctival tissue in HIE treated guinea pigs had mild mononuclear infiltration compared to the PBS-treated ones, which had intense conjunctival tissue inflammatory infiltration. HIE exhibited antiallergic effect possibly by immunomodulation or immunosuppression.
\end{abstract}

\section{Introduction}

Allergic conjunctivitis is a common problem that ophthalmic practitioners have to deal with, almost on daily basis, as it affects nearly $40 \%$ of the populace in advanced nation $[1,2]$. Various studies in Africa have indicated the prevalence of allergic conjunctivitis to range between 7.3 and $32 \%[3,4]$.

The conjunctiva is a dynamic immunologic tissue that suffers lymphoid hyperplasia in reaction to a stimulant such as pollens, animal dander, and other environmental antigens [5]. Allergic conjunctivitis (AC), therefore, is clinically characterized by pruritus, hyperemia, chemosis, tearing, and photophobia [6]. These clinical symptoms are the reason for the high morbidity associated with AC and consequential impact on quality of life of AC victims [7, 8]. Due to the large burden of AC and its spate of increase all over the world and across all ages, it possesses a great challenge to the health care resources of many countries $[9,10]$.

Allergic conjunctivitis is prompted by IgE-mediated immediate hypersensitivity reaction. Mast cell plays an important role in these allergic inflammations [11, 12]. Available medical therapies which include antihistamines, mast cell stabilizers, corticosteroids, nonsteroidal anti-inflammatory drugs, immunomodulatory agents, and allergen-specific immunotherapy could be rendered ineffective due to discomfort associated with administration of medications, intricacy of administration guidelines, perceived lack of efficacy by users, and/or adverse effects [13]. 
In the light of these bottlenecks associated with effective management of AC, current studies have focused attention on plants and natural products based therapeutic strategies in the bid to broaden treatment horizon, improve efficacy, and address safety concerns [14]. Heliotropium indicum L. (Boraginaceae), also known as Indian heliotrope, is one such plant used in the traditional management of conjunctivitis $[15,16]$. Although $H$. indicum is well-studied medicinal plant, its traditional use in treating ocular allergic inflammation is yet to be evaluated. This study therefore sought to evaluate the antiallergic effect and possible mechanism of action of whole plant aqueous extract of Heliotropium indicum L. in ovalbumin-induced allergic conjunctivitis in DunkinHartley guinea pigs.

\section{Materials and Methods}

2.1. Plant Collection. Heliotropium indicum was collected from the botanical gardens of the University of Cape Coast, Cape Coast, in the Central Region of Ghana $\left(5.1036^{\circ} \mathrm{N}\right.$, $1.2825^{\circ} \mathrm{W}$ ) in November 2012. It was identified and authenticated by a botanist at the School of Biological Sciences, College of Agricultural and Natural Science, University of Cape Coast, Cape Coast, Ghana, where a voucher specimen with number 4873 has been deposited at the herbarium for future reference.

2.2. Preparation of the Aqueous Extract of H. indicum (HIE). Whole plants of $H$. indicum were washed thoroughly with tap water and shade-dried. The dry plants were milled into coarse powder by a hammer mill (Schutte Buffalo, New York, NY). One and half kilograms of the plant powder was mixed with one liter of water. The mixture was Soxhlet-extracted at $80^{\circ} \mathrm{C}$ for $24 \mathrm{~h}$. The aqueous extract obtained was freeze-dried (Hull Freeze-Dryer/Lyophilizer 140 SQ, Warminster, PA). The powder (yield 12.2\%), labeled as $\mathrm{HIE}$, was stored at $4^{\circ} \mathrm{C}$ and reconstituted in normal saline to the desired concentration for dosing in this study.

2.3. Drugs and Chemicals. Ovalbumin (OVA) (Cayla-InvivoGen, Toulouse, France), aluminum hydroxide (Merck, Darmstadt, Germany), chloroform (Sigma-Aldrich, USA), cetirizine (McNeil Consumer Healthcare, Washington, USA), and prednisolone (Taizhou Baida Pharmaceutical Chemical Co., Ltd., China) were some chemicals used in this study.

2.4. Animal and Husbandry. Dunkin-Hartley guinea pigs (weight $300 \pm 25 \mathrm{~g}$ ) were kept in the Animal House of the School of Biological Sciences, University of Cape Coast, Ghana. The experimental animals were housed in aluminum cages $(34 \mathrm{~cm} \times 47 \mathrm{~cm} \times 18 \mathrm{~cm})$ with soft wood shavings as bedding, under ambient laboratory conditions (temperature $28^{\circ} \mathrm{C} \pm 2^{\circ} \mathrm{C}$, relative humidity $60-70 \%$, and a normal lightdark cycle). They were fed on a normal commercial pellet diet (Agricare Ltd., Kumasi, Ghana) and had access to water ad libitum.

2.5. Ethical and Biosafety Considerations. The study protocols were approved by the Institutional Review Board on Animal
Experimentation of the Faculty of Pharmacy and Pharmaceutical Sciences, Kwame Nkrumah University of Science and Technology, Kumasi, Ghana (Ethical Clearance number FPPS/PCOL/0030/2013). All activities performed during the studies conformed to accepted principles for laboratory animal use and care (EU directive of 1986: 86/609/EEC) and Association for Research in Vision and Ophthalmology Statement for Use of Animals in Ophthalmic and Vision Research. Biosafety guidelines for protection of personnel in the laboratory were observed.

2.6. Preliminary Phytochemical Screening. Screening was performed on HIE to ascertain the presence of phytochemicals using standard procedures described by Harborne [17] and Kujur et al. [18].

2.7. Ovalbumin-Induction Allergic Conjunctivitis (OIAC). OIAC was carried out as described by Shoji et al. [19] and Abokyi et al. [20]. Guinea pigs were sensitized by two intraperitoneal injections of $0.2 \mathrm{~mL}$ solution containing $100 \mu \mathrm{g}$ OVA and $0.01 \mathrm{mg}$ aluminum hydroxide in phosphate buffer saline ( $\mathrm{pH} 7.4)$ at an interval of 2 weeks. On day 8 after the sensitization, conjunctivitis was induced by topical instillation (challenge stage) of OVA (1.5 mg OVA in $10 \mu \mathrm{L}$ PBS) into the conjunctival sac of each eye. The topical challenge was repeated after 2 days. Physical and slit lamp (Marco II-B, Lombart Instrument, Japan) biomicroscopic ocular examinations were conducted. Hyperemia of palpebral conjunctiva, chemosis of bulbar conjunctiva, and lid swelling (clinical symptoms of AC) observed in the animal were an indication that $\mathrm{AC}$ had been induced.

\subsection{Effect of HIE on OIAC}

2.8.1. Grouping and Dosing. The animals with conjunctivitis were put into six groups $(n=5)$. Groups I-III were treated with 30,100 , and $300 \mathrm{mg} \mathrm{kg}^{-1} \mathrm{HIE}$, respectively, Group IV was treated with $10 \mathrm{mg} \mathrm{kg}^{-1}$ chlorpheniramine, and Group V received $30 \mathrm{mg} \mathrm{kg}^{-1}$ prednisolone, while Group VI (control group) was treated with $10 \mathrm{~mL} \mathrm{~kg}^{-1}$ PBS. A normal control group, Group VII (no sensitization and challenge, no interventionary treatment), was kept under experimental condition. All treatments were per os and were started $24 \mathrm{~h}$ after the last topical challenge. Treatment was twice daily (12hour interval) for one week.

2.8.2. Clinical Assessment of HIE in OIAC. Clinical examination was performed on days $1,3,5$, and 7 in the various groups of animals. Hyperemia of palpebral conjunctiva, chemosis of bulbar conjunctiva, and lid swelling were scored on a scale of $0-3$. The total of clinical scores for hyperemia of palpebral conjunctiva, chemosis of bulbar conjunctiva, and lid swelling was also evaluated as an overall clinical score [21].

2.8.3. Determination of Ovalbumin Specific IgE, IgG, and Total Serum IgE. Twenty-four hours after the last treatment had been administered, guinea pigs were anesthetized with chloroform and whole blood was collected from the jugular vein into pyrogenic free test tube (Indigo Instrument, 


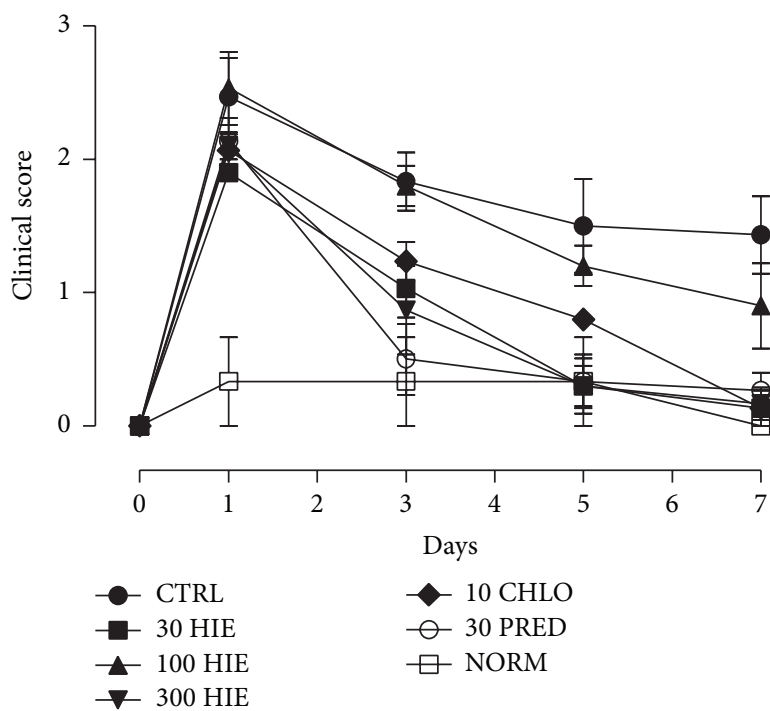

(a)

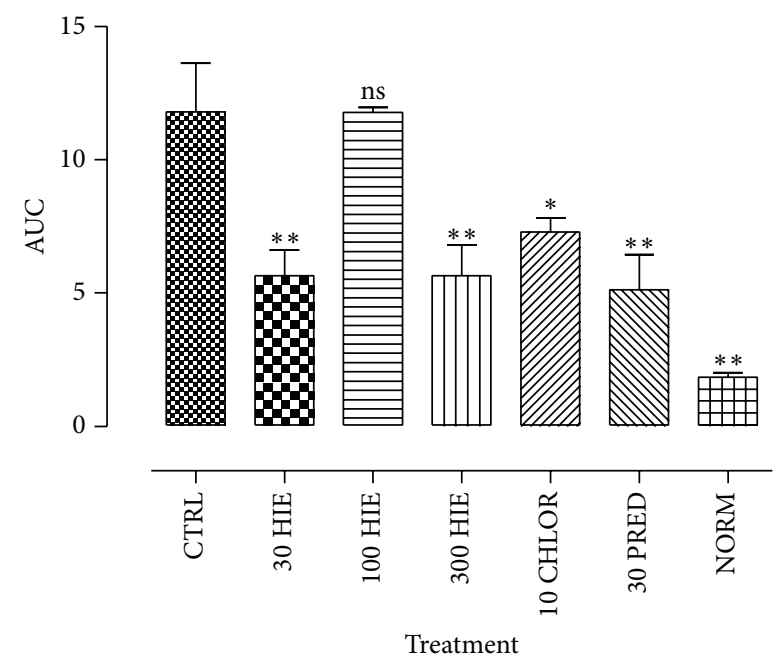

(b)

Figure 1: Time-course curves (a) and areas under the curve (b) for the effects of 30, 100, and $300 \mathrm{mg} \mathrm{kg}^{-1}$ of $\mathrm{HIE}$ and $10 \mathrm{mg} \mathrm{kg}^{-1}$ chlorpheniramine and $10 \mathrm{mg} \mathrm{kg}^{-1}$ prednisolone on OIAC in Dunkin-Hartley guinea pigs. Values plotted are mean $\pm \operatorname{SEM}(n=5) .{ }^{*} p \leq 0.01$; ${ }^{* *} p \leq 0.001$, ANOVA followed by Dunnett's multiple comparisons test.

Waterloo, Canada). Serum was prepared by centrifuging the clotted blood (temperature $25^{\circ} \mathrm{C}$, speed $3000 \mathrm{~g}$ ) for $5 \mathrm{~min}$ using a Mikro 220R machine (Hettich Zentrifuge, Tuttlingen, Germany). The serum was then subjected to EnzymeLinked Immunosorbent Assay (ELISA) (MyBioSource, San Diego, CA, USA) as per the manufacturer's instructions briefly described. This employed the double-sandwich ELISA technique. The precoated antibodies were either one of the following: guinea pig OVA sIgG, sIgE, and IgE monoclonal antibody and the detecting antibodies, a biotin labeled polyclonal antibody. In each case test samples and biotin labeled antibody were added to ELISA plate microwells. These were washed out with phosphate buffered saline (PBS). Avidin-peroxidase conjugates were then added to the ELISA wells; tetramethylbenzidine (TMB) substrate was used for coloring and washed out. TMB turned blue after intermittent incubation and finally yellow under the action of acid. The absorbances were then read at $450 \mathrm{~nm}$ using an URIT660 microplate reader (URIT Medical Electronic Co., Ltd., Guangxi, China). Each determination was in triplicate.

2.8.4. Histopathological Assessment. The eyeballs together with the conjunctiva and lids of animals from the various groups were exenterated and fixed in 10\% buffered formalin. Conjunctival tissue was stained with hematoxylin and eosin. Histopathological assessment was done by a specialist pathologist at Komfo Anokye Teaching Hospital, Kumasi, Ghana.

2.9. Statistical Analysis. The statistical analysis of data obtained was made using GraphPad Prism Version 5.0 (GraphPad Software, Inc., USA). Differences between treatment groups and the controls were estimated using OneWay Analysis of Variance (ANOVA) followed by Dunnett's Multiple Comparisons Test (post hoc test) at a confidence
TABLE 1: Results obtained after preliminary phytochemical screening of HIE.

\begin{tabular}{lc}
\hline Phytochemical tested for & Results obtained \\
\hline Anthraquinones & - \\
Tannins & + \\
Flavonoids & + \\
Alkaloids & + \\
Sterols & + \\
Glycosides & + \\
Saponins & + \\
Triterpenoids & - \\
\hline
\end{tabular}

“+” indicates presence; “-” indicates absence.

level of $95 \%$. Probability values less than or equal to $5 \%$ ( $p \leq$ $0.05)$ were considered significant.

\section{Results}

3.1. Phytochemical Screening. Preliminary phytochemistry showed that flavonoids, saponins, cyanogenic glycosides, sterols, tannins, and alkaloids were present in HIE (Table 1).

3.2. Effect of HIE on Clinical Signs of OIAC. The clinical scores for OIAC indicated a U-shaped effect of HIE in mitigating the clinical signs of allergic conjunctivitis. The 30 and $300 \mathrm{mg} \mathrm{kg}^{-1}$ significantly $(p \leq 0.001$ ) attenuated the clinical signs of allergic inflammation and not the $100 \mathrm{mg} \mathrm{kg}^{-1}$ (Figures 1(a) and 1(b)). Chlorpheniramine and prednisolone (reference drugs) significantly ( $p \leq 0.01-0.001$ ) attenuated the clinical signs of AC (Figures 1(a) and 1(b)). 


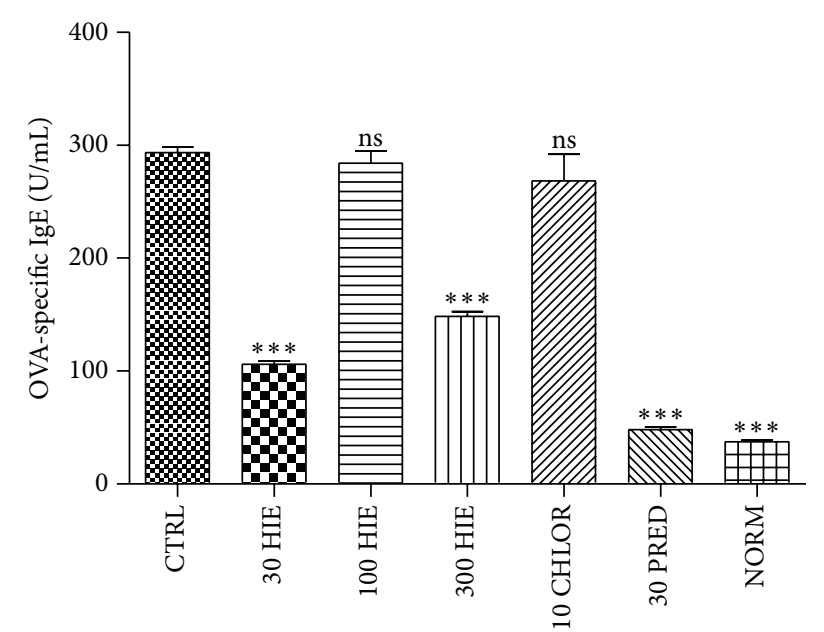

Treatment

Figure 2: The effect of 30,100 , and $300 \mathrm{mg} \mathrm{kg}^{-1} \mathrm{HIE}, 30 \mathrm{mg} \mathrm{kg}^{-1}$ prednisolone, and $10 \mathrm{mg} \mathrm{kg}^{-1}$ chlorpheniramine on OVA-specific serum IgE in OIAC in guinea pigs. ${ }^{* * *} p \leq 0.001$, ANOVA followed by Dunnett's post hoc test.

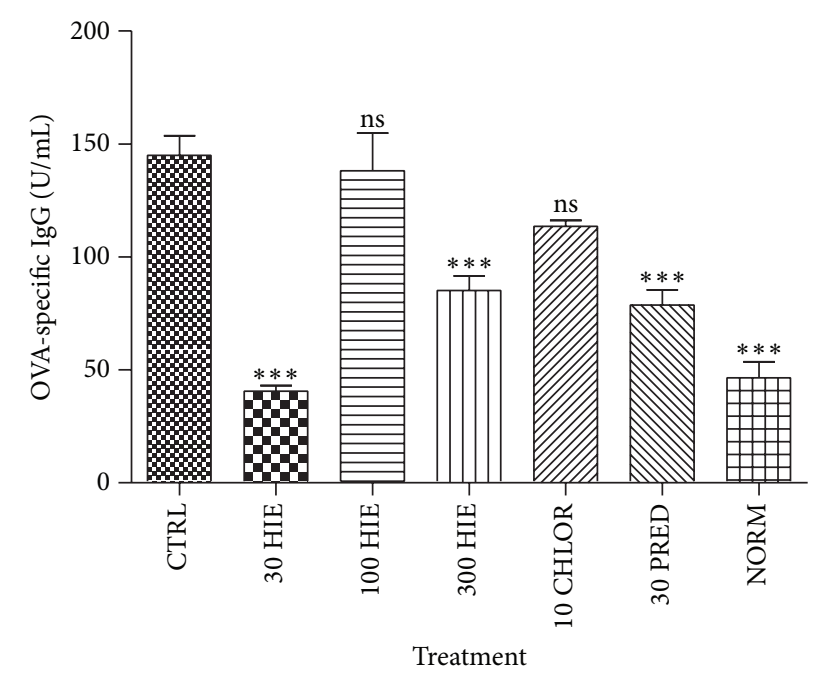

FIgURE 3: The effect of 30,100 , and $300 \mathrm{mg} \mathrm{kg}^{-1} \mathrm{HIE}, 30 \mathrm{mg} \mathrm{kg}^{-1}$ prednisolone, and $10 \mathrm{mg} \mathrm{kg}^{-1}$ chlorpheniramine on OVA-specific serum IgG in OIAC in guinea pigs. ${ }^{* * *} p \leq 0.001$, ANOVA followed by Dunnett's post hoc test.

3.3. HIE Effect on Sera OVA-Specific IgE, IgG, and Total IgE. HIE showed a U-shaped effect in decreasing ( $p \leq 0.01-0.001)$ sera OVA-specific IgE, IgG, and total IgE antibodies in serum. Prednisolone caused significant reduction $(p \leq 0.001)$ in the immunoglobulin, but chlorpheniramine did not (Figures 2$4)$.

3.4. Histopathological Assessment. The histopathological assessment showed remarkable signs of mononuclear infiltration in conjunctival tissue of the control (PBS treated) group. Treatment with 30 and $300 \mathrm{mg} \mathrm{kg}^{-1}$ showed a reduction in mononuclear infiltrations but not the $100 \mathrm{mg} \mathrm{kg}^{-1} \mathrm{HIE}$

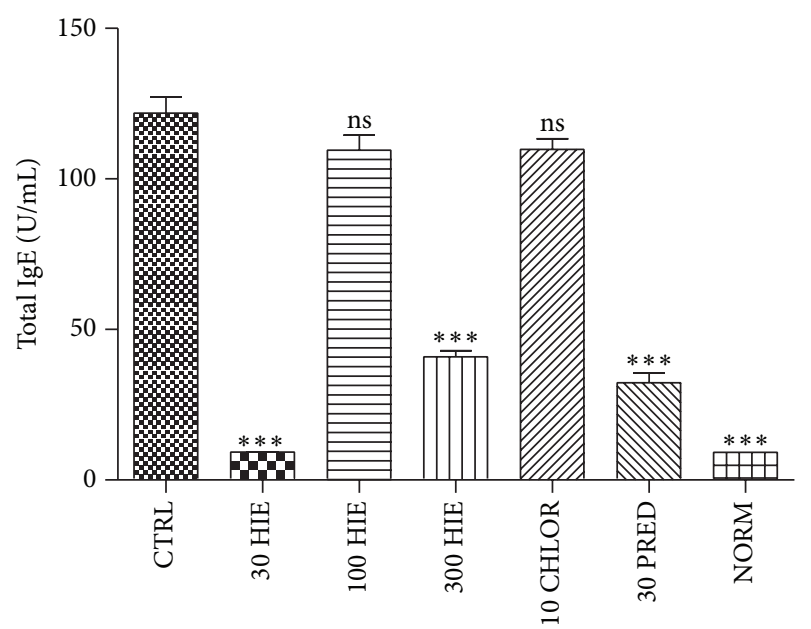

Treatment

FIgure 4: The effect of 30,100 , and $300 \mathrm{mg} \mathrm{kg}^{-1} \mathrm{HIE}, 30 \mathrm{mg} \mathrm{kg}^{-1}$ prednisolone, and $10 \mathrm{mg} \mathrm{kg}^{-1}$ chlorpheniramine on total serum IgE in OIAC in guinea pigs. ${ }^{* * *} p \leq 0.001$, ANOVA followed by Dunnett's post hoc test.

treated group. Prednisolone reduced the infiltration much more than chlorpheniramine (Figure 5).

\section{Discussion}

Ovalbumin-induced allergic conjunctivitis model in the guinea pig has been used in preclinical studies in screening for potential antiallergic agents [22]. It has been noted as an ideal model for both IgE mediated and non-IgE mediated allergic conjunctivitis [23]. This model of ocular allergic disease is typically related to type 1 hypersensitivity reactions. It is biphasic with the early-phase reaction driven primarily by mast cell degranulation and ensues right after exposure to the allergen; the late-phase reaction is marked by cell infiltration, mainly eosinophils, neutrophils, and lymphocytes, 6 to 24 hours after antigen application, corresponding to the clinical findings of allergic conjunctivitis [24]. Activation and conscription of inflammatory cells and the liberation of cytokines, chemokines, adhesion molecules, and proteases promote more serious chronic forms [25].

The low clinical scores obtained for the extract treated group justify the extract's potency in relieving the noisome symptoms associated with the underlying pathology of allergic conjunctivitis, the hallmark of most antiallergic agents. Although the U-shaped dose-response effect observed in clinical scores of ocular allergy remains unclear, it has been reported in several pharmacological investigations. This observation could be due to the inhibitory tendencies of the active phytochemical at that dose [26].

HIE reduced both allergen- (OVA-) specific IgG and IgE indicating a mechanistic deviation of activity from antihistaminic and mast cell stabilizing agents [20,27]. Treatment with chlorpheniramine irrespective of the favorable clinical outcome regarding the resolution of allergic inflammation had no significant effect on allergen-specific IgG, IgE, and total sera IgE. This is because the release of histamine 


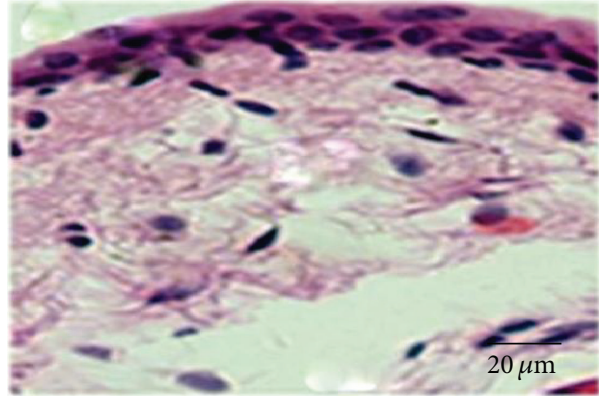

(a) Normal conjunctival tissue with normal epithelial architecture without evidence of mononuclear infiltration

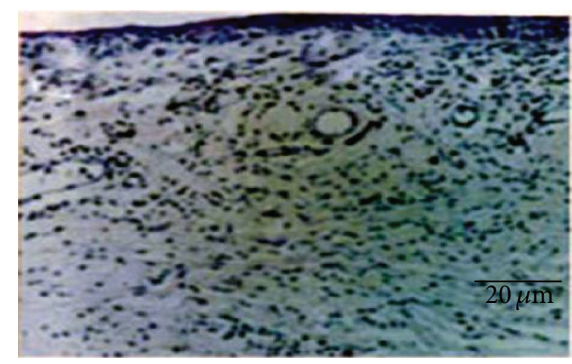

(c) PBS-treated conjunctival tissue with widespread infiltration of neutrophils and eosinophils

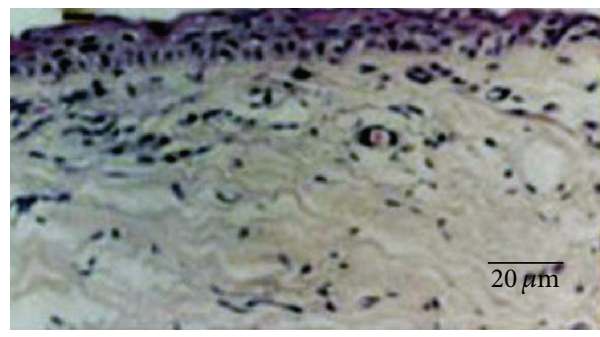

(e) $30 \mathrm{mg} \mathrm{kg}^{-1}$ HIE treated with mild infiltration of neutophilic and eosinophilic cells

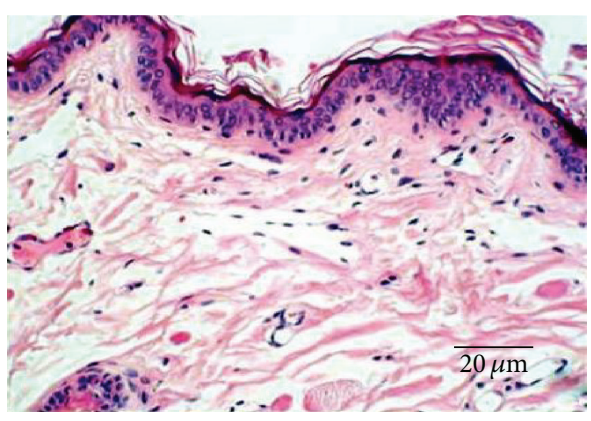

(b) $30 \mathrm{mg} \mathrm{kg}^{-1}$ prednisolone treated with mild mononuclear infiltration into the subepithelial tissue of the conjunctiva

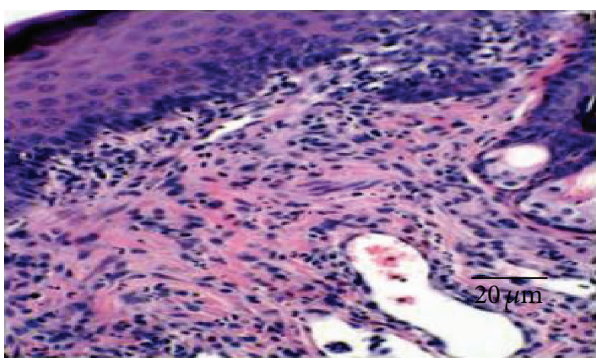

(d) $10 \mathrm{mg} \mathrm{kg}^{-1}$ chlorpheniramine treatment with remarkably unresolved inflammatory process seen as intense polymorphonuclear infiltration

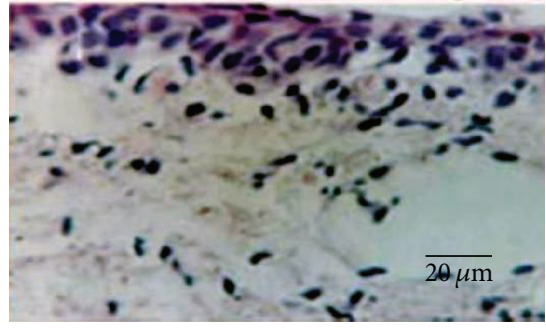

(f) $100 \mathrm{mg} \mathrm{kg}^{-1} \mathrm{HIE}$ treated conjunctival tissue with moderately diffuse neutrophils and eosinophils exudation

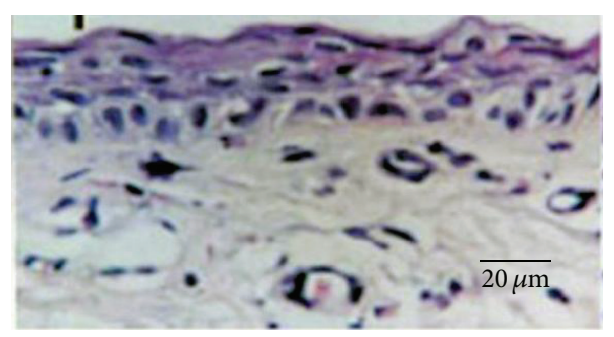

(g) $300 \mathrm{mg} \mathrm{kg}^{-1}$ HIE treated with mild neutophils and eosinophil infiltration in subepithelial conjunctival tissue

FIgURE 5: Photomicrographs of the conjunctival tissues in OIAC in guinea pigs treated with 30,100, and $^{2} 00 \mathrm{mg} \mathrm{kg}^{-1} \mathrm{HIE}, 30 \mathrm{mg} \mathrm{kg}^{-1}$ prednisolone, $10 \mathrm{mg} \mathrm{kg}^{-1}$ chlorpheniramine, and PBS, compared to that of normal guinea pigs.

whose receptors are the target for antihistaminic agents lies downstream immunoglobulin production. This therefore accounts for its ability to attenuate the clinical signs of allergic inflammation [28]. The extract treatment causing relevant reduction in allergen-specific immunoglobulins was similar to the effect of the steroid treatment (prednisolone). This presupposes that the extract may have immunomodulatory and or immunosuppressive effect $[13,29]$.

A number of immunomodulatory compounds have been isolated from natural products [30, 31]. Antioxidant-rich extracts have been found relevant as immunomodulatory or immunosuppressive agents and have been mainly used 
in control of the immune response in conditions like transplantation, autoimmune disorders, and alleviation of allergic diseases [31]. Some studies have already reported the antioxidant properties of both extract and different fractions of $H$. indicum which in effect suggest that HIE's antiallergic inflammatory effect could probably be due to its rich antioxidant constituents such as flavonoids, alkaloids, and tannins [32-34].

HIE treatment reduced serum levels of IgE which is one of the necessary ingredients in the promulgation of allergic inflammatory processes [35]. When an allergen (e.g., ovalbumin) is taken up by antigen presenting cells (e.g., allergen-specific B cell), via the cell surface immunoglobulin receptor, processed fragments are then presented in the context of major histocompatibility class II (MHC class II) to Th2 cells recognizing the allergen-MHC II complex. Activation of the allergen-specific Th2 cells results in the expression of IL-4, IL-13, and CD154 and introduction of class switching to IgE. Class switching, a process involved in the biosynthesis of immunoglobulins, is driven by allergens [36]. Class switching is ushered by T cells signalling. Nevertheless, basophils express high levels of IL-4, IL-13, and CD154 after stimulation and it has been postulated to play a role in polyclonal amplification of $\operatorname{IgE}$ production and in the differentiation of Th2 cells [37]. These immunoglobulins bind to high-affinity IgE receptor; FceR1 expressed on mast cells and basophils as tetramers $\left(\alpha \beta \gamma_{2}\right)$ and on antigen presenting cells, at much lower levels, as trimers $\left(\alpha \gamma_{2}\right)$ leading to degranulation of mast cells [38]. Studies have shown that the density of human basophil and mast cell FceR1 expression is associated with serum IgE levels [39]. Mast cell degranulation is dependent on Syk kinase responsible for signaling proceedings subsequent to mast cells and basophils stimulation. This assertion is supported by recent finding indicating that Syk kinase deficient mast cells and basophils do not undergo degranulation after FceR1 aggregation [40]. This therefore opens a window of opportunity for therapeutic exploration. The extract in this case indicates a mechanistic efficacy in reducing serum OVA allergen-specific and total IgE levels.

\section{Conclusion}

The aqueous whole plant extract of Heliotropium indicum exhibits antiallergic effect in ovalbumin-induced conjunctivitis in guinea pigs via a probable immunomodulating or immunosuppressive action supporting its traditional use in treatment of conjunctivitis.

\section{Disclosure}

This paper results from research towards a Ph.D. (optometry) degree in the discipline of optometry at the University of KwaZulu-Natal under the supervision of Dr. George A. Koffuor and cosupervision of Professor Paul Ramkissoon.

\section{Conflict of Interests}

The authors declare no conflict of interests whatsoever.

\section{Acknowledgments}

The authors are grateful to the management and staff of Life Science Diagnostic Centre, Cape Coast, for permitting the authors to use their facility for carrying aspects of this study. This study was partly funded by the University of Cape Coast.

\section{References}

[1] K. Singh and L. Bielory, "Ocular allergy: a national epidemiologic study," Journal of Allergy and Clinical Immunology, vol. 119, supplement 1, p. S154, 2007.

[2] K. Singh, S. Axelrod, and L. Bielory, "The epidemiology of ocular and nasal allergy in the United States, 1988-1994," Journal of Allergy and Clinical Immunology, vol. 126, no. 4, pp. 778-783.e6, 2010.

[3] S. Abokyi, G. A. Koffuor, M. Ntodie, S. Kyei, and L. Gyanfosu, "Epidemiological profile and pharmacological management of allergic conjunctivitis: a study in Ghana," International Journal of Pharmaceutical and Biomedical Research, vol. 3, no. 4, pp. 195201, 2012.

[4] K. N. Malu, "Allergic conjunctivitis in Jos-Nigeria," Nigerian Medical Journal, vol. 55, no. 2, pp. 166-170, 2014.

[5] P. Isaacson and D. H. Wright, "Extranodal malignant lymphoma arising from mucosa-associated lymphoid tissue," Cancer, vol. 53, no. 11, pp. 2515-2524, 1984.

[6] S. M. Whitcup, C.-C. Chan, D. A. Luyo, P. Bo, and Q. Li, “Topical cyclosporine inhibits mast cell-mediated conjunctivitis," Investigative Ophthalmology and Visual Science, vol. 37, no. 13, pp. 2686-2693, 1996.

[7] A. D. Pitt, A. F. Smith, L. Lindsell, L. W. Voon, P. W. Rose, and N. J. Bron, "Economic and quality-of-life impact of seasonal allergic conjunctivitis in Oxfordshire," Ophthalmic Epidemiology, vol. 11, no. 1, pp. 17-33, 2004.

[8] J. Palmares, L. Delgado, M. Cidade, M. J. Quadrado, and H. P. Filipe, "Allergic conjunctivitis: a national cross-sectional study of clinical characteristics and quality of life," European Journal of Ophthalmology, vol. 20, no. 2, pp. 257-264, 2010.

[9] S. Bonini, "Allergic conjunctivitis: the forgotten disease," Chemical Immunology and Allergy, vol. 91, pp. 110-120, 2006.

[10] K. Singh and L. Bielory, "Ocular allergy: a national epidemiologic study," Journal of Allergy and Clinical Immunology, vol. 119, no. 1, supplement 1, p. S154, 2007.

[11] L. Bielory, "Allergic and immunologic disorders of the eye. Part I: immunology of the eye," Journal of Allergy and Clinical Immunology, vol. 106, no. 5, pp. 805-816, 2000.

[12] T. Tominaga, D. Miyazaki, S.-I. Sasaki et al., "Blocking mast cell-mediated type i hypersensitivity in experimental allergic conjunctivitis by monocyte chemoattractant protein-1/CCR2," Investigative Ophthalmology and Visual Science, vol. 50, no. 11, pp. 5181-5188, 2009.

[13] C. Córdova, B. Gutiérrez, C. Martínez-García et al., "Oleanolic acid controls allergic and inflammatory responses in experimental allergic conjunctivitis," PLoS ONE, vol. 9, no. 4, Article ID e91282, 2014.

[14] B. B. Cota, C. M. Bertollo, and D. M. de Oliveira, "Anti-allergic potential of herbs and herbal natural products-activities and patents," Recent Patents on Endocrine, Metabolic \& Immune Drug Discovery, vol. 7, no. 1, pp. 26-56, 2013. 
[15] M. Rahmatullah, A. K. Das, M. A. H. Mollik et al., "An ethnomedicinal survey of Dhamrai sub-district in Dhaka District, Bangladesh," American-Eurasian Journal of Sustainable Agriculture, vol. 3, no. 4, pp. 881-888, 2009.

[16] E. Roeder and H. Wiedenfeld, "Plants containing pyrrolizidine alkaloids used in the Traditional Indian medicine-including Ayurveda," Pharmazie, vol. 68, no. 2, pp. 83-92, 2013.

[17] J. B. Harborne, Phytochemical Methods: A Guide to Modern Techniques of Plant Analysis, Chapman and Hall, London, UK, 3rd edition, 1998.

[18] R. S. Kujur, V. Singh, M. Ram et al., "Antidiabetic activity and phytochemical screening of crude extract of Stevia rebaudiana in alloxan-induced diabetic rats," Pharmacognosy Research, vol. 2, no. 4, pp. 258-263, 2010.

[19] J. Shoji, N. Inada, N. Takaura, and M. Sawa, "Histological study of allergic conjunctivitis. 1. Study on the adhesion molecules to allergic conjunctivitis," Journal of Japanese Ophthalmological Society, vol. 99, no. 2, pp. 129-134, 1995.

[20] S. Abokyi, G. A. Koffuor, S. Kyei, E. A. Asiamah, C. N. Atobiga, and A. Awuah, "Antiallergic effect of an aqueous leaf extract of Pistia stratiotes in murine model of ovalbumin-induced allergic conjunctivitis," Pharmacognosy Research, vol. 6, no. 4, pp. 274279, 2014

[21] A. Ozaki, Y. Seki, A. Fukushima, and M. Kubo, "The control of allergic conjunctivitis by suppressor of cytokine signaling (SOCS) 3 and SOCS5 in a murine model," The Journal of Immunology, vol. 175, no. 8, pp. 5489-5497, 2005.

[22] J. Shouji, K. Saito, N. Takaura, N. Inada, and M. Sawa, "Histological study of allergic conjunctivitis report 2. Time course of allergic conjunctival inflammation," Nihon Ganka Kiyo, vol. 46, no. 10, pp. 1015-1020, 1995.

[23] D. A. Groneberg, L. Bielory, A. Fischer, S. Bonini, and U. Wahn, "Animal models of allergic and inflammatory conjunctivitis," Allergy, vol. 58, no. 11, pp. 1101-1113, 2003.

[24] B. P. Bielory, T. P. O’Brien, and L. Bielory, "Management of seasonal allergic conjunctivitis: guide to therapy," Acta Ophthalmologica, vol. 90, no. 5, pp. 399-407, 2012.

[25] H. Hirai, K. Tanaka, O. Yoshie et al., "Prostaglandin D2 selectively induces chemotaxis in T helper type 2 cells, eosinophils, and basophils via seven-transmembrane receptor CRTH2," Journal of Experimental Medicine, vol. 193, no. 2, pp. 255-261, 2001.

[26] D. Wu, J. R. Cypser, A. I. Yashin, and T. E. Johnson, “The Ushaped response of initial mortality in Caenorhabditis elegans to mild heat shock: does it explain recent trends in human mortality?" Journals of Gerontology-Series A Biological Sciences and Medical Sciences, vol. 63, no. 7, pp. 660-668, 2008.

[27] Y. Ohashi, Y. Nakai, A. Tanaka et al., "Serum levels of specific IgE, soluble interleukin-2 receptor, and soluble intercellular adhesion molecule-1 in seasonal allergic rhinitis," Annals of Allergy, Asthma \& Immunology, vol. 79, no. 3, pp. 213-220, 1997.

[28] G. M. Walsh, "The anti-inflammatory effects of levocetirizineare they clinically relevant or just an interesting additional effect?" Allergy, Asthma \& Clinical Immunology, vol. 5, article 14, 2009.

[29] G. R. Duddukuri, R. Y. Vasudeva, D. N. Rao, and R. A. Rao, "Immunomodulation of ovalbumin-specific IgG and other classes of antibody response by honey in mice," Indian Journal of Clinical Biochemistry, vol. 16, no. 1, pp. 89-94, 2001.

[30] V. P. Kurup and C. S. Barrios, "Immunomodulatory effects of curcumin in allergy," Molecular Nutrition and Food Research, vol. 52, no. 9, pp. 1031-1039, 2008.
[31] M.-H. Boskabady, R. Keyhanmanesh, S. Khameneh, Y. Doostdar, and M.-R. Khakzad, "Potential immunomodulation effect of the extract of Nigella sativa on ovalbumin sensitized guinea pigs," Journal of Zhejiang University: Science B, vol. 12, no. 3, pp. 201-209, 2011.

[32] R. M. Ammal and V. S. Bai, "Free radical scavenging activity of Heliotropium indicum leaves," International Journal of Research in Plant Science, vol. 4, no. 3, pp. 63-67, 2014.

[33] Y. Begum, "Antibacterial, antioxidant and cytotoxic activities of Heliotropium indicum," The Experiment, vol. 23, no. 1, pp. 15641569, 2014.

[34] R. R. Pragada, S. Rao Ethadi, B. Yasodhara, V. S. Praneeth Dasari, and T. Mallikarjuna Rao, "In-vitro antioxidant and antibacterial activities of different fractions of Heliotropium indicum L," Journal of Pharmacy Research, vol. 5, no. 2, pp. 1051-1053, 2012.

[35] P. Smith and D. R. Ownby, "Clinical significance of IgE," in Middleton's Allergy: Principles and Practice, N. Adkinson, B. S. Bochner, W. W. Busse, S. T. Holgate, R. F. Lemanske, and F. E. R. Simons, Eds., Mosby Elsevier, 7th edition, 2009.

[36] K. D. Stone, C. Prussin, and D. D. Metcalfe, "IgE, mast cells, basophils, and eosinophils," Journal of Allergy and Clinical Immunology, vol. 125, supplement 2, no. 2, pp. S73-S80, 2010.

[37] H. C. Oettgen, "Immunobiology of IgE and IgE receptors," in Middleton's Allergy: Principles and Practice, N. F. Adkinson, B. S. Bochner, A. W. Burks et al., Eds., Mosby Elsevier, 8th edition, 2014.

[38] H. J. Gould and B. J. Sutton, "IgE in allergy and asthma today," Nature Reviews Immunology, vol. 8, no. 3, pp. 205-217, 2008.

[39] D. MacGlashan Jr., "IgE receptor and signal transduction in mast cells and basophils," Current Opinion in Immunology, vol. 20, no. 6, pp. 717-723, 2008.

[40] A. M. Gilfillan and J. Rivera, "The tyrosine kinase network regulating mast cell activation," Immunological Reviews, vol. 228, no. 1, pp. 149-169, 2009. 


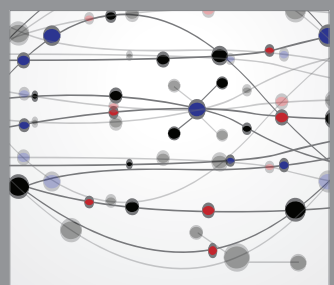

The Scientific World Journal
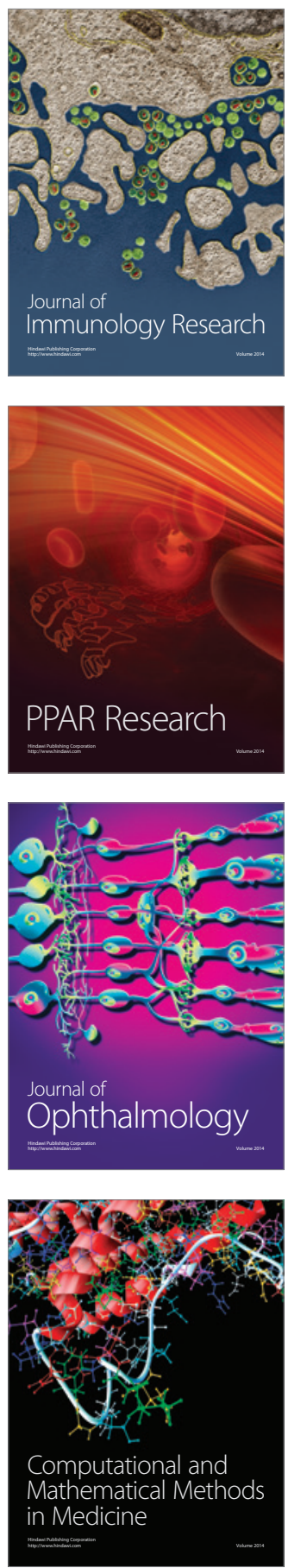

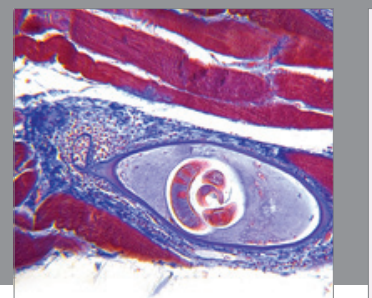

Gastroenterology

Research and Practice
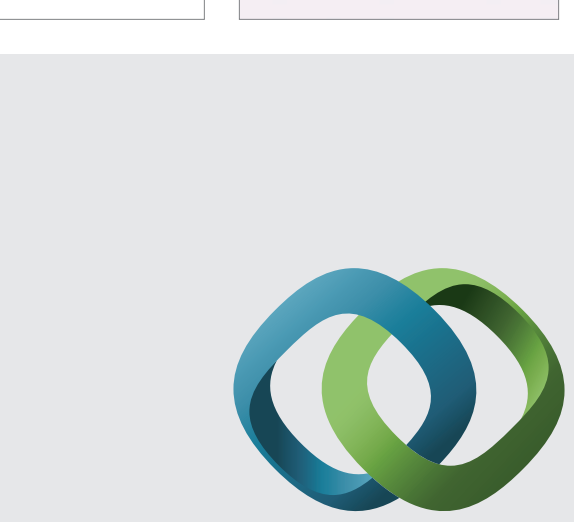

\section{Hindawi}

Submit your manuscripts at

http://www.hindawi.com
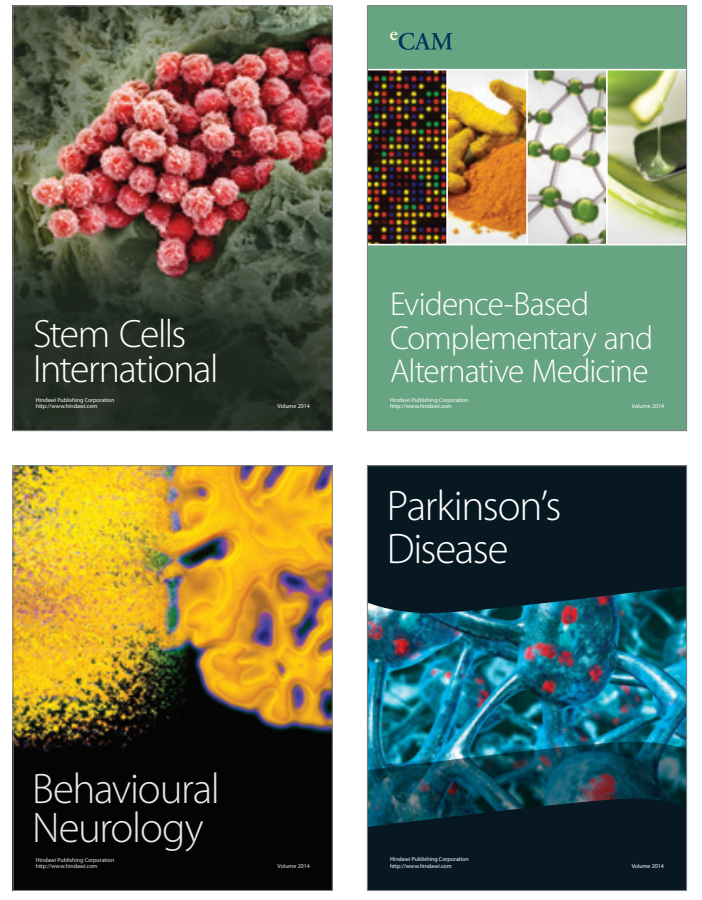
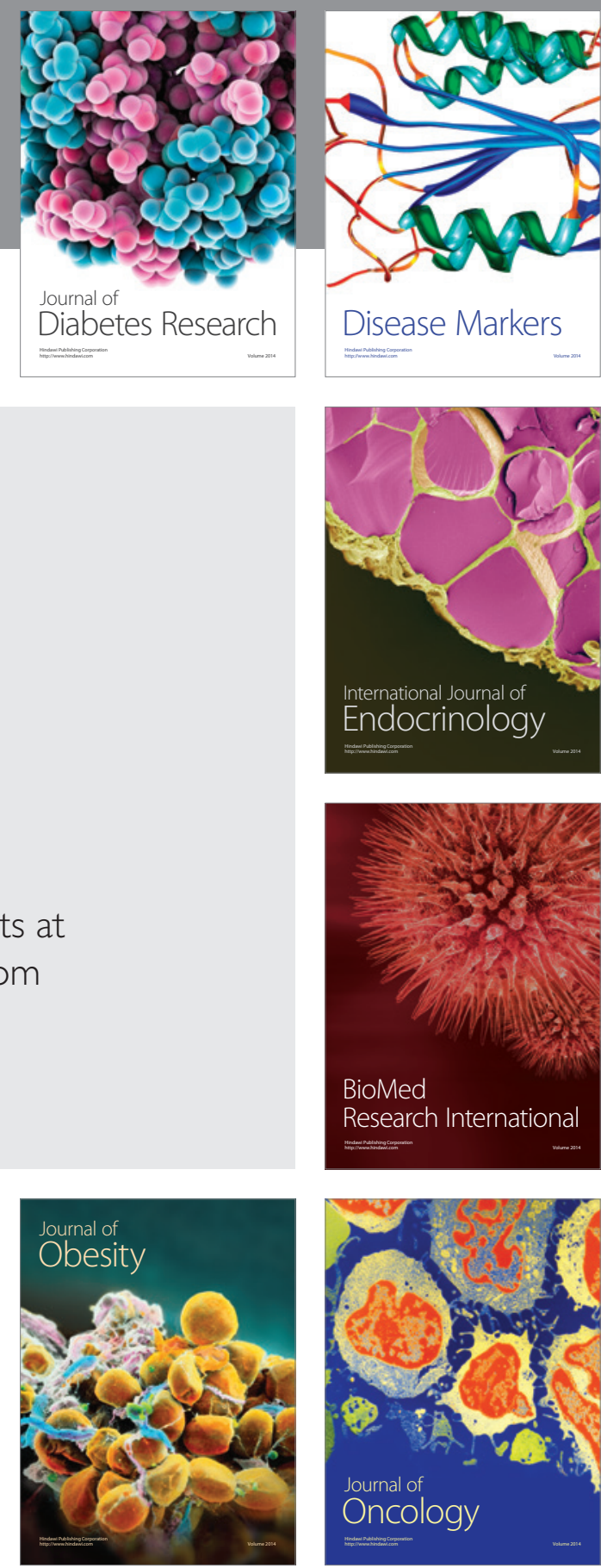

Disease Markers
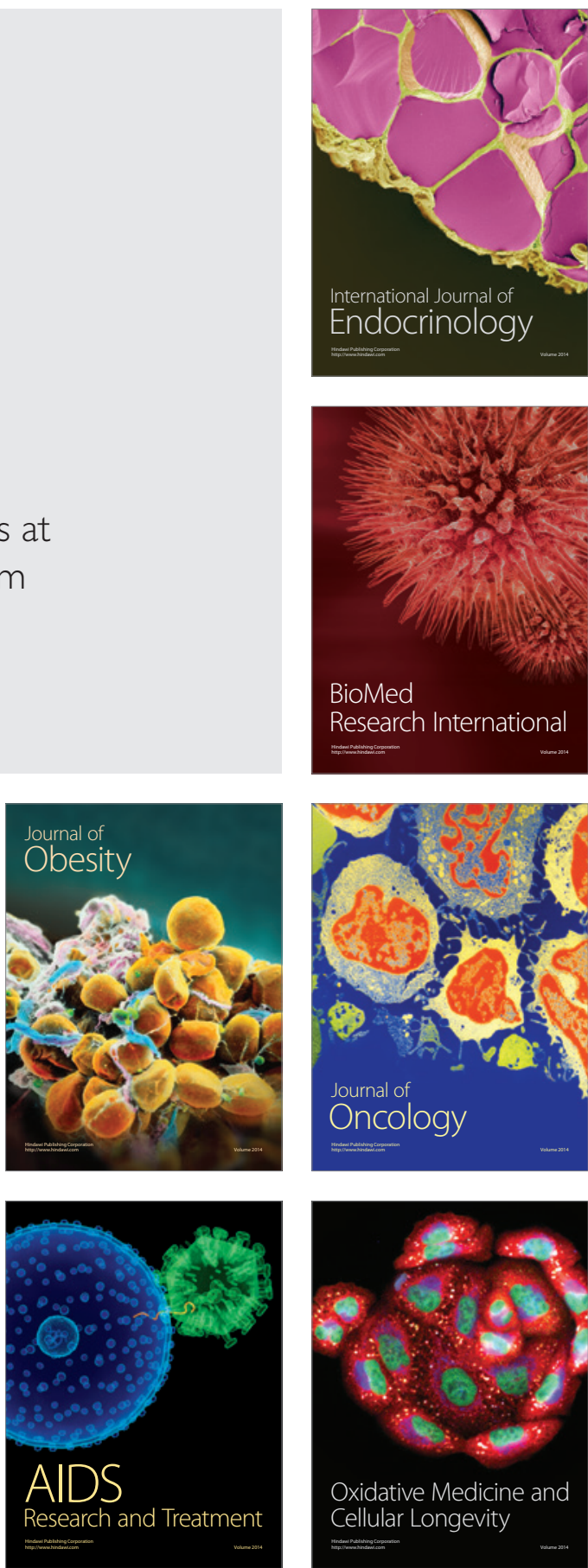